\title{
Effect of Voluntary Wheel Running on Striatal Dopamine Level and Neurocognitive Behaviors after Molar Loss in Rats
}

\author{
Linlin Zhang, ${ }^{1}$ Yi Feng, ${ }^{2}$ Wenliang Ji, ${ }^{1}$ Jianzhang Liu, ${ }^{3}$ and Kun Liu ${ }^{1,4}$ \\ ${ }^{1}$ Capital University of Physical Education and Sports, Beijing 100191, China \\ ${ }^{2}$ Beijing Xicheng District Desheng Community Health Service Center, Beijing 100120, China \\ ${ }^{3}$ Peking University School and Hospital of Stomatology, Beijing 100081, China \\ ${ }^{4}$ Department of Psychiatry, Yale University School of Medicine, New Haven, CT 06511, USA
}

Correspondence should be addressed to Jianzhang Liu; liujianzhang@bjmu.edu.cn and Kun Liu; kun.liu@yale.edu

Linlin Zhang and Yi Feng contributed equally to this work.

Received 9 June 2017; Revised 25 August 2017; Accepted 2 October 2017; Published 5 December 2017

Academic Editor: Francesca Trojsi

Copyright (C) 2017 Linlin Zhang et al. This is an open access article distributed under the Creative Commons Attribution License, which permits unrestricted use, distribution, and reproduction in any medium, provided the original work is properly cited.

\begin{abstract}
The aim of the present study is to evaluate the effect of voluntary wheel running on striatal dopamine level and behavior of cognition and emotion in molar loss rats. Twenty-four Sprague-Dawley rats were enrolled in this study and randomly divided into following 4 groups: control group (C group), molar loss group (ML group), 1-week physical exercise before molar loss group (1W-ML group), and 4-week physical exercise before molar loss group (4W-ML group). The rats both in $4 \mathrm{~W}-\mathrm{ML}$ and 1W-ML groups were placed in the voluntary running wheel in order to exercise for 4 weeks and 1 week, respectively. Then, the rats in $4 \mathrm{~W}-\mathrm{ML}, 1 \mathrm{~W}-\mathrm{M}$, and ML groups received bilateral molar loss operation. After 10 days, striatal dopamine level was detected by in vivo microdialysis coupled with high-performance liquid chromatography (HPLC) and electrochemical detection. All the rats received behavior test after microdialysis detection. The behavior tests including passive avoidance test were used to assess cognition and elevated plus maze test for emotion. The results indicated that voluntary wheel running promoted striatal dopamine level in rats of molar loss. Behavioral data indicated that voluntary wheel running promoted cognition and emotion recovery after molar loss. Therefore, we concluded physical exercise significantly improved the neurocognitive behaviors and increased the striatal dopamine level after molar loss in rats.
\end{abstract}

\section{Introduction}

It is well established that tooth loss is a known risk factor of Alzheimer's disease (AD) [1]. As a common disorder in senior population, loss of teeth could adversely affect human cognition and emotion $[2,3]$. Clinical medicine has established that tooth loss in patients can induce neuronal cell loss and memory impairment $[4,5]$. Animal research also demonstrated that molar loss can cause the functional deterioration of cognition [6]. Previous studies have demonstrated that the rat with molar loss broke the balance of the cholinergic neuronal system and caused the impairment of cognition [7]. In addition, a preliminary quantitative study revealed that wide range of emotional effects was caused by tooth loss, such as loss of self-confidence and anxiety [8]. Further studies have shown that physical exercise, aerobic fitness exercise in particularly, had a positive effect on multiple aspects of brain function [9-11]. Neurochemistry studies indicated that physical exercise increased the antioxidant ability and glucose level to enhance cognition and emotion [12-14]. Neurobiology research also confirmed that aerobic exercise predominately employed the action of BDNF and the new growth of synaptic plasticity [15-17]. In addition, dopamine acts as a classic neurotransmitter in the brain, which plays an important role in cognitive and emotive aspects [18-20]. Numerous studies have shown that dopamine degeneration caused significant alteration in cognitive and emotive function by medicating striatal dopamine pathways [21-22]. Striatum is one of the four major dopamine pathways in the brain, partially involved in reward and in the reinforcement of memory consolidation. Degeneration of dopamineproducing neurons in striatum complex leads to diminished 
concentrations of dopamine in the nigrostriatal pathway, leading to reduce function and the characteristic symptoms, such as motor ability and cognitive impairment [23-25]. Therefore, this study was designed to explore the effect of voluntary wheel running on striatal dopamine level and neurocognitive behaviors after molar loss in rats. These findings may provide a theoretical basis for the clinical prevention of Alzheimer's disease.

\section{Materials and Methods}

2.1. Animals. Adult male Sprague-Dawley rats (3 months of age, weighting $300 \pm 50 \mathrm{~g}$ at the time of surgery) were obtained from Experimental Animal Center of Peking University. Rats $(n=24)$ were enrolled in this study and randomly divided into following 4 groups: control group (C group, $n=6$ ), molar loss group (ML group, $n=6$ ), 1-week physical exercise before molar loss group (1W-ML group, $n=6$ ), and 4-week physical exercise before molar loss group ( $4 \mathrm{~W}$-ML group, $n=6$ ). The rats in both $4 \mathrm{~W}-\mathrm{ML}$ and $1 \mathrm{~W}$-ML groups were placed in the voluntary running wheel in order to exercise for 4 weeks or 1 week. Then, the rats in 4W-ML, 1W-ML, and ML groups received bilateral molar loss operation. In the $\mathrm{C}$ group, bilateral maxillary molar teeth remained intact. All rats were housed under $12 \mathrm{~h}$ light/dark cycle and had a sufficient amount of food and water.

2.2. Voluntary Wheel Running. The rats in both $4 \mathrm{~W}-\mathrm{ML}$ and $1 \mathrm{~W}-\mathrm{ML}$ groups received voluntary wheel running. Two rat groups were given free access to running wheels (wheel circumference, $100 \mathrm{~cm}$; Harvard Apparatus) in their cages for 4 weeks or 1 week. A magnetic counter was installed to the running wheel in order to record wheel revolutions [26]. The distance was obtained by wheel revolutions multiplied by the circumference of the wheel. Those rats that cannot adapt new circumstances will be removed.

2.3. Molar Loss Surgery. Bilateral maxillary molar teeth were extracted from rats in the $4 \mathrm{~W}-\mathrm{ML}, 1 \mathrm{~W}-\mathrm{ML}$, and ML groups after being anesthetized with chloral hydrate $(350 \mathrm{mg} / \mathrm{kg}$, i.p.). The rats in the $\mathrm{C}$ group were anesthetized, but no teeth were extracted. To provide a suitable recovery time after teeth extraction, experimental dentures were fitted to rats. Experimental dentures were produced from an impression made of silicone impression material and a resin tray. Occlusal adjustments were made until maxillomandibular incisor contacts were obtained [27].

2.4. In Vivo Microdialysis and High-Performance Liquid Chromatography. In vivo microdialysis was performed by implanting microdialysis probe into the striatum through the guide cannula by continuously perfusing with artificial cerebrospinal fluid $(126 \mathrm{mM} \mathrm{NaCl}, 2.4 \mathrm{mM} \mathrm{KCl}, 1.1 \mathrm{mM}$ $\mathrm{CaCl}_{2}, 0.85 \mathrm{mM} \mathrm{MgCl}_{2}, 27.5 \mathrm{mM} \mathrm{NaHCO}_{3}, 0.5 \mathrm{mM} \mathrm{Na}_{2} \mathrm{SO}_{4}$, and $0.5 \mathrm{mM} \mathrm{KH}_{2} \mathrm{PO}_{4}, \mathrm{pH}=7.0$ ) at a flow rate of $2 \mu \mathrm{L} / \mathrm{min}$ driven by a microinjection pump (CMA/100, CMA Microdialysis AB, Stockholm, Sweden). After $90 \mathrm{~min}$, microdialysate in the striatum were collected for 60 minutes; each sample was collected in a $250 \mu \mathrm{L}$ tubes for $10 \mathrm{~min}$ for a total of 6 tubes. Each tube was placed in an ice box containing $15 \mathrm{~L}$ of $10 \mathrm{mmol}$

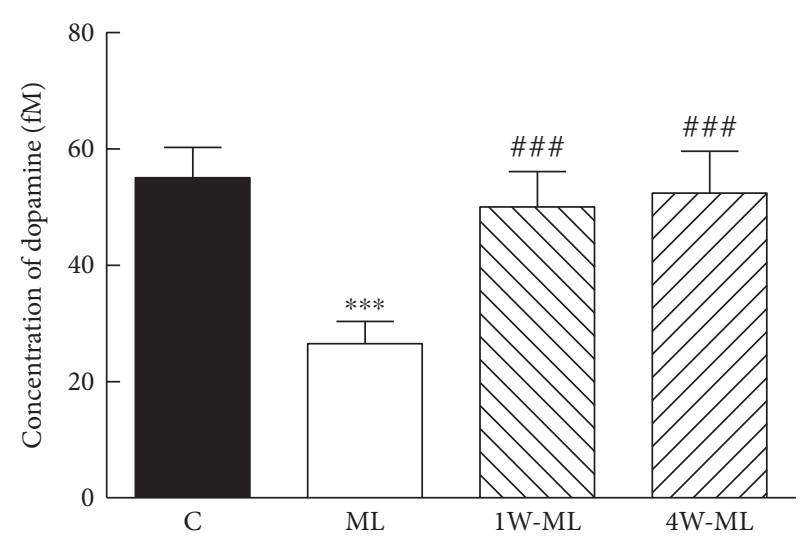

Figure 1: Dynamic changes of striatal dopamine level in each group. ${ }^{* * *} P<0.01$ compared with $\mathrm{C}$ group. ${ }^{\# \# \#} P<0.01$ compared with ML group.

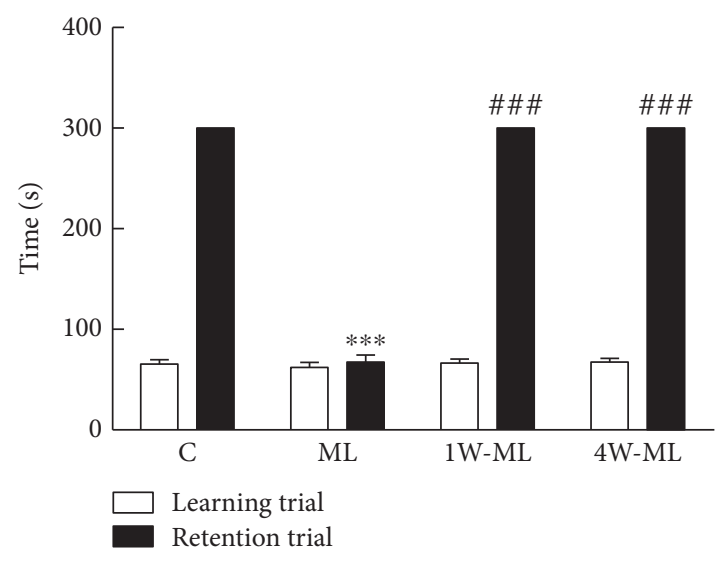

FIgURE 2: The latency time of rats in learning trial and retention trial. ${ }^{* * *} P<0.001$ compared with $\mathrm{C}$ group. ${ }^{\# \# \#} P<0.01$ compared with ML group.

HCL. Then, dopamine level in the samples was measured using HPLC with electrochemical detection. The flow rate of the mobile phase $\left(50 \mathrm{mM} \mathrm{NaH}_{2} \mathrm{PO}_{3}, 2 \mathrm{mM}\right.$ decanesulfonic acid, $0.7 \mathrm{mM}$ ethylenediaminetetraacetic acid, $11 \% \mathrm{v} / \mathrm{v}$ acetonitrile, and $11 \% v / v$ methanol, $\mathrm{pH}=6.0$ ) was $1 \mu \mathrm{L} / \mathrm{min}$.

2.5. Passive Avoidance Test. Cognitive function was assessed by passive avoidance test [28]. After the learning trail, the retention test was measured $24 \mathrm{~h}$ after the learning trial. Each animal was put in an illuminated compartment, and the door opened after 2 minutes. Latency to enter the dark compartment was recorded to a maximum of $300 \mathrm{~s}$. Animals that did not enter the dark chamber during the retention test were allotted a latency of $300 \mathrm{~s}$ [29].

2.6. Elevated Plus Maze Test. Emotion was assessed by elevated plus maze test [30]. The elevated plus maze was made of plastic and consisted of two white open arms $(25 \times 8 \mathrm{~cm})$, two black enclosed arms $(25 \times 8 \times 20 \mathrm{~cm})$, and a central platform $(8 \times 8 \times 8 \mathrm{~cm})$ in the form of a cross. The maze was placed $50 \mathrm{~cm}$ above the floor. Rats were individually placed in the center with their heads directed toward one of the closed arms. The total time spent in each arm or in the 


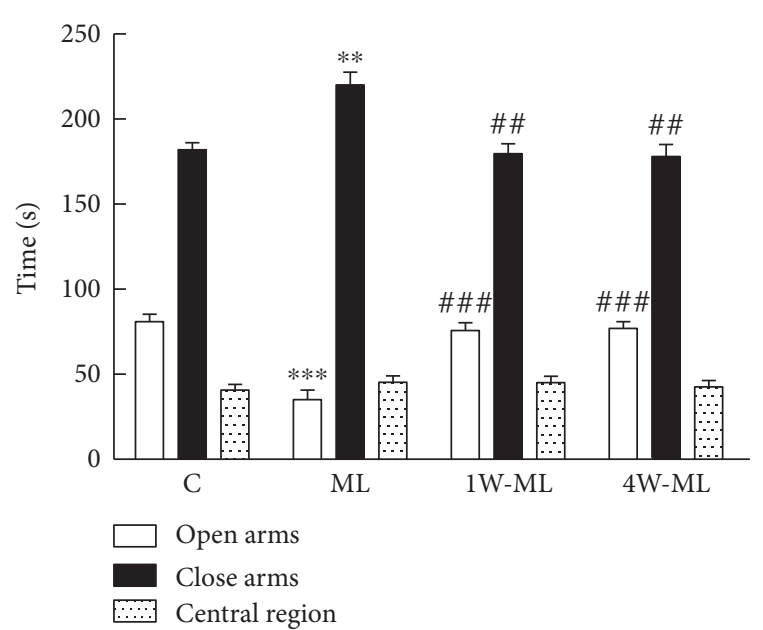

(a)

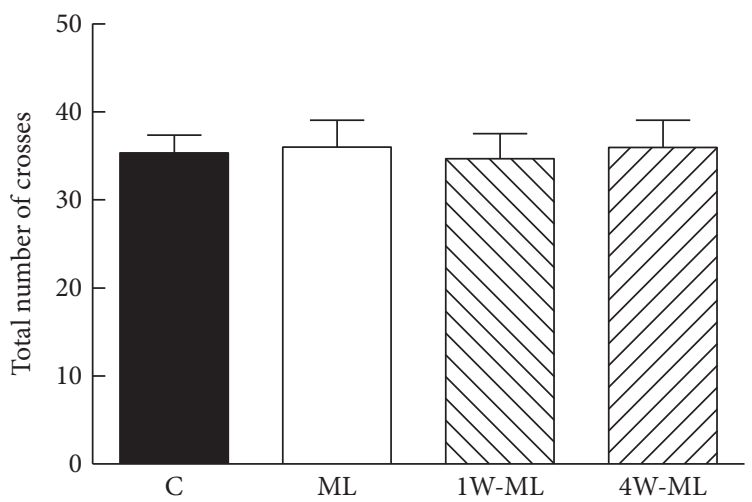

(b)

Figure 3: (a) Time spent of four rat groups in each arm. ${ }^{* * *} P<0.001$ and ${ }^{* *} P<0.01$ compared with $C$ group. ${ }^{\# \#} P<0.001$ and ${ }^{\# \#} P<0.01$ compared with ML group. (b) Total number of crosses in each group.

center and the total number of entries into each arm were analyzed by video monitoring for $5 \mathrm{~min}$. After $5 \mathrm{~min}$, rats were removed from the maze and returned to their home cage. The maze was then cleaned with a solution of $70 \%$ ethyl alcohol and permitted to dry between tests [31].

2.7. Statistical Analysis. Data were analyzed by GraphPad Prism 5. A two-way analysis of variance (ANOVA) was used to analyze the data. The comparison of cognition and emotion was made with two-tailed Student's $t$ test.

\section{Results}

3.1. Dynamic Changes of Striatal Dopamine Level in Each Group. Figure 1 shows dynamic changes of striatal dopamine level in each group. The dopamine level in $\mathrm{C}, \mathrm{ML}, 1 \mathrm{~W}-\mathrm{ML}$, and $4 \mathrm{~W}$-ML groups was $55.02 \pm 9.05 \mathrm{fmol}, 26.48 \pm 6.67 \mathrm{fmol}$, $50.01 \pm 10.52 \mathrm{fmol}, 52.34 \pm 12.54 \mathrm{fmol}$, respectively. Compared with $\mathrm{C}$ group, the extracellular dopamine level of $\mathrm{ML}$ group significantly decreased $(P<0.001)$. Compared with ML group, the extracellular dopamine level of $1 \mathrm{~W}-\mathrm{ML}$ and $4 \mathrm{~W}-\mathrm{ML}$ group significantly increased $(P<0.001)$. However, the extracellular dopamine level has no significant difference between $1 \mathrm{~W}-\mathrm{ML}$ and $4 \mathrm{~W}-\mathrm{ML}$ groups $(P>0.05)$. The results indicated that 1 -week or 4 -week volunteer wheel running increased striatum dopamine level after molar loss.

3.2. Passive Avoidance Test. Figure 2 shows that the latency time of passive avoidance test in each group. In learning trial, the time in $\mathrm{C}, \mathrm{ML}, 1 \mathrm{~W}-\mathrm{ML}$, and $4 \mathrm{~W}-\mathrm{ML}$ group was $65.5 \pm 11.89 \mathrm{~s}, 62 \pm 13.41 \mathrm{~s}, 66.5 \pm 8.56 \mathrm{~s}$, and $67.5 \pm 10.27 \mathrm{~s}$ and $300 \mathrm{~s}, 67.5 \pm 16.69 \mathrm{~s}, 300 \mathrm{~s}$, and $300 \mathrm{~s}$ in retention trial. There was no significant difference in the learning trial for each group $(P>0.05)$. Compared with $C$ group, the retention time of ML group was significantly shorter $(P<0.001)$. Compared with ML group, the retention time of $1 \mathrm{~W}-\mathrm{ML}$ and $4 \mathrm{~W}-\mathrm{ML}$ groups was significantly longer $(P<0.001)$.
However, the retention time has no significant difference between $1 \mathrm{~W}-\mathrm{ML}$ and $4 \mathrm{~W}-\mathrm{ML}$ groups $(P>0.05)$. The results indicated that 1 -week and 4 -week volunteer wheel running can promote cognition after molar loss.

3.3. Elevated Plus Maze Test. Figure 3(a) shows that the time spent of each rat groups in each arm. Compared with $C$ group, the time spent of open arms in the ML group was significantly shorter $(P<0.001)$, adversely close arms $(P<0.01)$. Compared with ML group, the time spent of open arms in the $1 \mathrm{~W}-\mathrm{ML}$ and $4 \mathrm{~W}-\mathrm{ML}$ groups was significantly longer $(P<0.001)$, adversely close arms $(P<0.01)$. However, the time spent in each arm has no difference between $1 \mathrm{~W}-\mathrm{ML}$ and $4 \mathrm{~W}-\mathrm{ML}$ groups $(P>0.05)$. Meanwhile, there was no significant difference in the central region time for each group $(P>0.05)$. Figure $3(\mathrm{~b})$ shows that total number of crosses in three groups. But there was no significant difference in the total number of crosses for each group $(P>0.05)$. The results indicated that 1 -week or 4-week volunteer wheel running can promote emotion after molar loss.

\section{Discussion}

Alzheimer's disease (AD) can be considered as the most common cause of cognitive dysfunction among the aged, and tooth loss might be a risk factor for Alzheimer-type dementia [32-34]. New advances have shown that tooth loss caused the decline of cognition [35-37]. Previous research used passive avoid test to evaluate cognition, which shows that molar loss may cause accumulation of the amyloid cascade in the brain that leads to cognitive impairment [38]. Thus, we chose passive avoidance test to assess cognition in rats. We also choose elevated plus maze test to evaluate emotion. The results show that the cognition and emotion were worse after molar loss. Therefore, we successfully established the rat model of cognitive and emotive dysfunction after 
molar loss in this experiment. Previous study has shown that molar loss-induced cognitive and emotive impairments are related to neural cell loss [38-39]. In this study, we also demonstrated that molar loss-induced cognitive and emotive impairments are associated with the decrease of striatal dopamine level. Clinical studies have demonstrated that cognitive impairment had pathophysiology of dopamine system by the loss of midbrain neurons that synthesize the neurotransmitter dopamine [40-41]. Animal study also demonstrated that depression and anxiety might be associated with a specific loss of dopamine innervation in the limbic system [42]. Thus, it is reasonable to suggest that the decrease of striatal dopamine level can be one of the important reason of cognitive and emotive impairment after molar loss.

However, therapeutic strategies for the cognitive and emotive impairment after molar loss have not been well established so far. Molecular chemistry and biology highlight the promoted effect of physical exercise on cognition and emotion [43-45]. Some research has shown that exercise increased synaptic plasticity and the level of BGF and promoted cognition [46-47]. Other research also have shown that exercise can enhance cell proliferation, thereby alleviating anxiety-like behavior and improve emotion [48-49]. Especially, studies also indicated that physical exercise, voluntary wheel running in particularly, can be one of the best ways to promote cognition and emotion [50-51]. So, the present study chose voluntary wheel running as intervention approach. Our behavioral data indicated that voluntary wheel running promoted cognitive and emotive recovery after molar loss. As reported previously, physical exercise promoted the new growth of synaptic plasticity and the level of brain glucose and improve cognition and emotion thereafter [52-54]. In our research, we demonstrate that 4-week and 1 -week voluntary wheel running promoted cognitive and emotive recovery after molar loss is associated with the increase of striatal dopamine level. Previous studies have demonstrated that physical exercise increased antioxidant defense and dopamine levels [55-57]. The increased dopamine level is related to recovery of cognitive and emotive impairments. Thus, we suggest that the increased of striatal dopamine level can be one of the reasons to induce that voluntary wheel running promotes cognition and emotion after molar loss in rats.

It is worth to mention that there was no difference between 4 weeks and 1 week of physical exercise-promoted cognition and emotion after molar loss in dopamine concentration aspect. Since previous research have found that small amount of physical exercise could be beneficial to cognitive function, it is reasonable that 1 week of physical exercise is enough to promote cognition and emotion after molar loss in dopamine concentration aspect. Although we did not find difference of dopamine level in striatum after 1 week and 4 weeks of physical exercise in our experiment condition, it is still possible that dopamine dynamic change in different brain regions could be induced by different physical exercise processes. In addition, whether there is difference in other aspects, such as other cognitive behavioral models or cellular levels, needs to be studied further.

\section{Conclusions}

Physical exercise significantly promoted the cognition and emotion in rats of molar loss by increasing the striatal dopamine level. However, it is necessary to further study other neurochemicals related to dopaminergic system to elucidate more underlying mechanisms of physical exercisepromoted cognition and emotion after molar loss.

\section{Conflicts of Interest}

The authors declare that there is no conflict of interests.

\section{Acknowledgments}

The authors gratefully acknowledge the financial support by NSF of China (Grant no. 21475089), Innovation Platform of Beijing Municipality (PXM2015_014206_000053, PXM 2015_014206_000072, and PXM2015_014206_000051).

\section{References}

[1] Q. Pang, X. Hu, X. Li, J. Zhang, and Q. Jiang, "Behavioral impairments and changes of nitric oxide and inducible nitric oxide synthase in the brains of molarless KM mice," Behavioural Brain Research, vol. 278, pp. 411-416, 2015.

[2] K. J. Joshipura, C. W. Douglass, and W. C. Willett, "Possible explanations for the tooth loss and cardiovascular disease relationship," Annals of Periodontology, vol. 3, no. 1, pp. 175-183, 1998.

[3] J. Luo, B. Wu, Q. Zhao et al., "Association between tooth loss and cognitive function among 3063 Chinese older adults: a community-based study," PLoS One, vol. 10, no. 3, article e0120986, 2015.

[4] H. Nilsson, J. Berglund, and S. Renvert, "Tooth loss and cognitive functions among older adults," Acta Odontologica Scandinavica, vol. 72, no. 8, pp. 639-644, 2014.

[5] D. Lexomboon, M. Trulsson, I. Wårdh, and M. G. Parker, "Chewing ability and tooth loss: association with cognitive impairment in an elderly population study," Journal of the American Geriatrics Society, vol. 60, no. 10, pp. 1951-1956, 2012.

[6] K. Yamazaki, N. Wakabayashi, T. Kobayashi, and T. Suzuki, "Effect of tooth loss on spatial memory and TrkB-mRNA levels in rats," Hippocampus, vol. 18, no. 6, pp. 542-547, 2008.

[7] T. Kato, T. Usami, Y. Noda, M. Hasegawa, M. Ueda, and T. Nabeshima, "The effect of the loss of molar teeth on spatial memory and acetylcholine release from the parietal cortex in aged rats," Behavioural Brain Research, vol. 83, no. 1-2, pp. 239-242, 1997.

[8] D. Davis, J. Fiske, B. Scott, and D. R. Radford, "The emotional effects of tooth loss: a preliminary quantitative study," British Dental Journal, vol. 188, no. 09, pp. 503-506, 2000.

[9] C. H. Hillman, K. I. Erickson, and A. F. Kramer, "Be smart, exercise your heart: exercise effects on brain and cognition," Nature Reviews Neuroscience, vol. 9, no. 1, pp. 58-65, 2008.

[10] B. K. Tivadar, "Physical activity improves cognition: possible explanations," Biogerontology, vol. 18, no. 4, pp. 477-483, 2017. 
[11] Z. Radak, S. Kumagai, A. W. Taylor, H. Naito, and S. Goto, "Effects of exercise on brain function: role of free radicals," Applied Physiology, Nutrition, and Metabolism, vol. 32, no. 5, pp. 942-946, 2007.

[12] N. Okudan and M. Belviranli, "Effects of exercise training on hepatic oxidative stress and antioxidant status in aged rats," Archives of Physiology and Biochemistry, vol. 122, no. 4, pp. 180-185, 2016.

[13] M. A. Moro, A. Almeida, J. P. Bolaños, and I. Lizasoain, "Mitochondrial respiratory chain and free radical generation in stroke," Free Radical Biology \& Medicine, vol. 39, no. 10, pp. 1291-1304, 2005.

[14] F. T. A. Pijlman, G. Wolterink, and J. M. Van Ree, "Physical and emotional stress have differential effects on preference for saccharine and open field behaviour in rats," Behavioural Brain Research, vol. 139, no. 1-2, pp. 131-138, 2003.

[15] S. Vaynman, Z. Ying, and F. Gomez-Pinilla, "Hippocampal BDNF mediates the efficacy of exercise on synaptic plasticity and cognition," European Journal of Neuroscience, vol. 20, no. 10, pp. 2580-2590, 2004.

[16] C. H. Chae, H. C. Lee, S. L. Jung et al., "Swimming exercise increases the level of nerve growth factor and stimulates neurogenesis in adult rat hippocampus," Neuroscience, vol. 212, pp. 30-37, 2012.

[17] R. Šumec, P. Filip, K. Sheardová, and M. Bareš, "Psychological benefits of nonpharmacological methods aimed for improving balance in Parkinson's disease: a systematic review," Behavioural Neurology, vol. 2015, Article ID 620674 , 16 pages, 2015.

[18] S. K. Mittal and C. Eddy, "The role of dopamine and glutamate modulation in Huntington disease," Behavioural Neurology, vol. 26, no. 4, pp. 255-263, 2013.

[19] A. Costa, A. Peppe, I. Mazzù, M. Longarzo, C. Caltagirone, and G. A. Carlesimo, "Dopamine treatment and cognitive functioning in individuals with Parkinson's disease: the "cognitive flexibility" hypothesis seems to work," Behavioural Neurology, vol. 2014, Article ID 260896, 11 pages, 2014.

[20] A. Venkatraman, B. L. Edlow, and M. H. Immordino-Yang, "The brainstem in emotion: a review," Frontiers in Neuroanatomy, vol. 11, p. 15, 2017.

[21] A. Nieoullon, "Dopamine and the regulation of cognition and attention," Progress in Neurobiology, vol. 67, no. 1, pp. 53-83, 2002.

[22] A. Nieoullon and A. Coquerel, "Dopamine: a key regulator to adapt action, emotion, motivation and cognition," Current Opinion in Neurology, vol. 16, Supplement 2, pp. S3-S9, 2003.

[23] R. A. Wise, "Roles for nigrostriatal—not just mesocorticolimbic-dopamine in reward and addiction," Trends in Neurosciences, vol. 32, no. 10, pp. 517-524, 2009.

[24] A. Gröger, R. Kolb, R. Schäfer, and U. Klose, "Dopamine reduction in the substantia nigra of Parkinson's disease patients confirmed by in vivo magnetic resonance spectroscopic imaging," PLoS One, vol. 9, no. 1, article e84081, 2014.

[25] D. Wang, X. Liu, and D. Qiao, "Modulatory effect of subthalamic nucleus on the development of fatigue during exhausting exercise: an in vivo electrophysiological and microdialysis study in rats," Journal of Sports Science \& Medicine, vol. 11, no. 2, pp. 286-293, 2012.

[26] S. Fediuc, J. E. Campbell, and M. C. Riddell, "Effect of voluntary wheel running on circadian corticosterone release and on HPA axis responsiveness to restraint stress in
Sprague-Dawley rats," Journal of Applied Physiology, vol. 100, no. 6, pp. 1867-1875, 2006.

[27] S. Iida, T. Hara, D. Araki et al., "Memory-related gene expression profile of the male rat hippocampus induced by teeth extraction and occlusal support recovery," Archives of Oral Biology, vol. 59, no. 2, pp. 133-141, 2014.

[28] O. Y. Calhan and V. Seyrantepe, "Mice with catalytically inactive cathepsin a display neurobehavioral alterations," Behavioural Neurology, vol. 2017, Article ID 4261873, 11 pages, 2017.

[29] M. Tahamtan, M. Allahtavakoli, M. Abbasnejad et al., "Exercise preconditioning improves behavioral functions following transient cerebral ischemia induced by 4 -vessel occlusion (4-VO) in rats," Archives of Iranian Medicine, vol. 16, no. 12, pp. 697-704, 2013.

[30] L. L. Furlanetti, M. D. Döbrössy, I. A. Aranda, and V. A. Coenen, "Feasibility and safety of continuous and chronic bilateral deep brain stimulation of the medial forebrain bundle in the naive Sprague-Dawley rat," Behavioural Neurology, vol. 2015, Article ID 256196, 13 pages, 2015.

[31] D. B. Pahaye, E. N. Bum, G. S. Taïwé et al., "Neuroprotective and antiamnesic effects of Mitragyna inermis willd (Rubiaceae) on scopolamine-induced memory impairment in mice," Behavioural Neurology, vol. 2017, Article ID 5952897, 11 pages, 2017.

[32] C. Jenner, G. Reali, M. Puopolo, and M. C. Silveri, "Can cognitive and behavioural disorders differentiate frontal variant-frontotemporal dementia from Alzheimer's disease at early stages?," Behavioural Neurology, vol. 17, no. 2, pp. 8995, 2006.

[33] S. Sil and T. Ghosh, "Cox-2 plays a vital role in the impaired anxiety like behavior in colchicine induced rat model of Alzheimer disease," Behavioural Neurology, vol. 2016, Article ID 1501527, 8 pages, 2016.

[34] B. C. Dickerson and R. A. Sperling, "Large-scale functional brain network abnormalities in Alzheimer's disease: insights from functional neuroimaging," Behavioural Neurology, vol. 21, no. 1-2, pp. 63-75, 2009.

[35] X. Xu, B. Cao, J. Wang, T. Yu, and Y. Li, "Decision-making deficits associated with disrupted synchronization between basolateral amygdala and anterior cingulate cortex in rats after tooth loss," Progress in Neuro-Psychopharmacology and Biological Psychiatry, vol. 60, pp. 26-35, 2015.

[36] E. J. Yang, U. Mahmood, H. Kim et al., “Alterations in protein phosphorylation in the amygdala of the 5XFamilial Alzheimer's disease animal model," Journal of Pharmacological Sciences, vol. 133, no. 4, pp. 261-267, 2017.

[37] M. Onozuka, K. Watanabe, S. Nagasaki et al., "Impairment of spatial memory and changes in astroglial responsiveness following loss of molar teeth in aged SAMP8 mice," Behavioural Brain Research, vol. 108, no. 2, pp. 145-155, 2000.

[38] H. Oue, Y. Miyamoto, S. Okada et al., "Tooth loss induces memory impairment and neuronal cell loss in APP transgenic mice," Behavioural Brain Research, vol. 252, pp. 318-325, 2013.

[39] S. Sakamoto, T. Hara, A. Kurozumi et al., "Effect of occlusal rehabilitation on spatial memory and hippocampal neurons after long-term loss of molars in rats," Journal of Oral Rehabilitation, vol. 41, no. 10, pp. 715-722, 2014.

[40] L. Bäckman, L. Nyberg, U. Lindenberger, S. C. Li, and L. Farde, "The correlative triad among aging, dopamine, and cognition: 
current status and future prospects," Neuroscience \& Biobehavioral Reviews, vol. 30, no. 6, pp. 791-807, 2006.

[41] J. H. Kim, J. M. Auerbach, J. A. Rodríguez-Gómez et al., "Dopamine neurons derived from embryonic stem cells function in an animal model of Parkinson's disease," Nature, vol. 418, no. 6893, pp. 50-56, 2002.

[42] P. Remy, M. Doder, A. Lees, N. Turjanski, and D. Brooks, "Depression in Parkinson's disease: loss of dopamine and noradrenaline innervation in the limbic system," Brain, vol. 128, no. 6, pp. 1314-1322, 2005.

[43] J. J. Annesi, "Effects of minimal exercise and cognitive behavior modification on adherence, emotion change, selfimage, and physical change in obese women," Perceptual and Motor Skills, vol. 91, no. 1, pp. 322-336, 2000.

[44] F. Nozariyan, P. Shafiniya, V. Shahvali, and M. A. Makiyani, "Emotion changes during exercise in males' physical education student," vol. 9, 2016.

[45] T. Nozawa, Y. Taki, A. Kanno et al., "Effects of different types of cognitive training on cognitive function, brain structure, and driving safety in senior daily drivers: a pilot study," Behavioural Neurology, vol. 2015, Article ID 525901, 18 pages, 2015.

[46] A. S. Aguiar Jr., A. A. Castro, E. L. Moreira et al., "Short bouts of mild-intensity physical exercise improve spatial learning and memory in aging rats: involvement of hippocampal plasticity via AKT, CREB and BDNF signaling," Mechanisms of Ageing and Development, vol. 132, no. 11-12, pp. 560-567, 2011.

[47] T. Kobila, Q. R. Liu, K. Gandhi, M. Mughal, Y. Shaham, and H. van Praag, "Running is the neurogenic and neurotrophic stimulus in environmental enrichment," Learning \& Memory, vol. 18, pp. 605-609, 2011.

[48] S. J. Lee, T. W. Kim, H. K. Park et al., "Postnatal treadmill exercise alleviates prenatal stress-induced anxiety in offspring rats by enhancing cell proliferation through 5-Hydroxytryptamine 1 A receptor activation," International Neurourology Journal, vol. 20, Supplement 1, pp. S57-S64, 2016.

[49] E. E. Bernstein and R. J. McNally, "Acute aerobic exercise hastens emotional recovery from a subsequent stressor," Health Psychology, vol. 36, no. 6, pp. 560-567, 2017.

[50] X. Zhao, J. Aronowski, S. J. Liu et al., "Wheel-running modestly promotes functional recovery after a unilateral cortical lesion in rats," Behavioural Neurology, vol. 16, no. 1, pp. 41-49, 2005.

[51] Y. Lin, X. Lu, J. Dong et al., "Involuntary, forced and voluntary exercises equally attenuate neurocognitive deficits in vascular dementia by the BDNF-pCREB mediated pathway," Neurochemical Research, vol. 40, no. 9, pp. 1839-1848, 2015.

[52] M. C. Lee, M. Okamoto, Y. F. Liu et al., "Voluntary resistance running with short distance enhances spatial memory related to hippocampal BDNF signaling," Journal of Applied Physiology, vol. 113, no. 8, pp. 1260-1266, 2012.

[53] A. C. McKee, D. H. Daneshvar, V. E. Alvarez, and T. D. Stein, "The neuropathology of sport," Acta Neuropathologica, vol. 127, no. 1, pp. 29-51, 2014.

[54] X. Xiao, Q. Lin, W. L. Lo et al., "Cerebral reorganization in subacute stroke survivors after virtual reality-based training: a preliminary study," Behavioural Neurology, vol. 2017, Article ID 6261479, 8 pages, 2017.
[55] M. Harvey, K. Muir, I. Reeves et al., "Long term improvements in activities of daily living in patients with hemispatial neglect," Behavioural Neurology, vol. 23, no. 4, pp. 237-239, 2010.

[56] M. Asghar, L. George, and M. F. Lokhandwala, "Exercise decreases oxidative stress and inflammation and restores renal dopamine D1 receptor function in old rats," American Journal of Physiology-Renal Physiology, vol. 293, no. 3, pp. F914-F919, 2007.

[57] L. Pruimboom, C. L. Raison, and F. A. J. Muskiet, "Physical activity protects the human brain against metabolic stress induced by a postprandial and chronic inflammation," Behavioural Neurology, vol. 2015, Article ID 569869, 11 pages, 2015. 


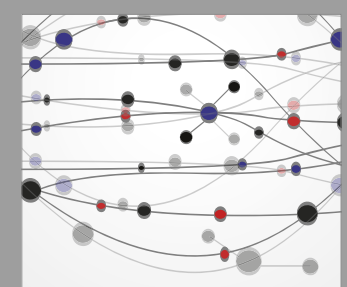

The Scientific World Journal
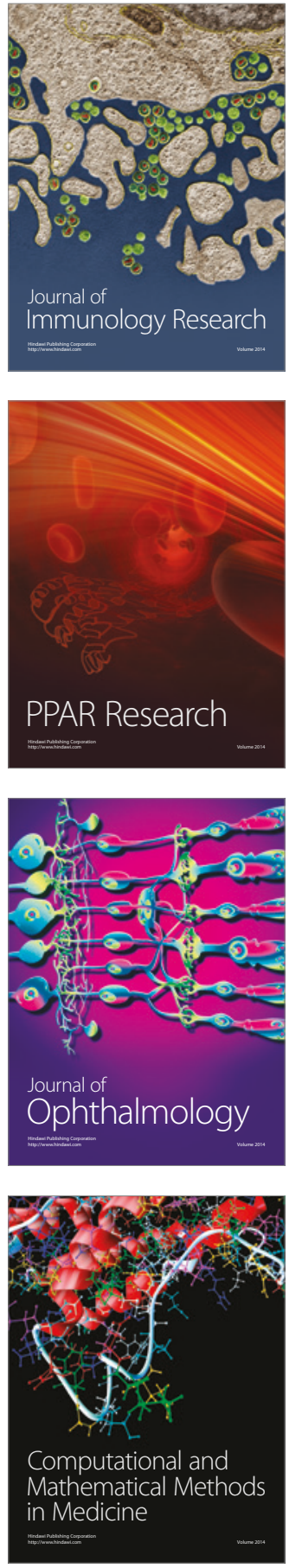

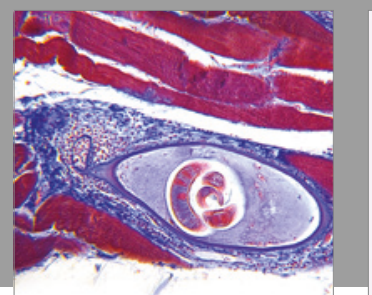

Gastroenterology Research and Practice
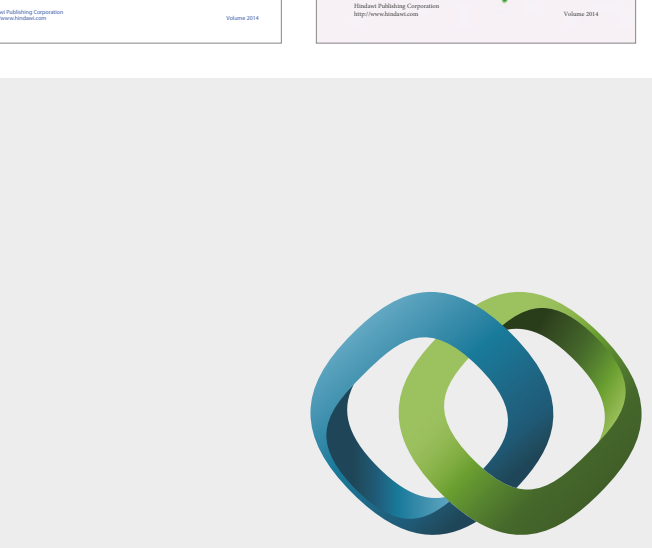

\section{Hindawi}

Submit your manuscripts at

https://www.hindawi.com
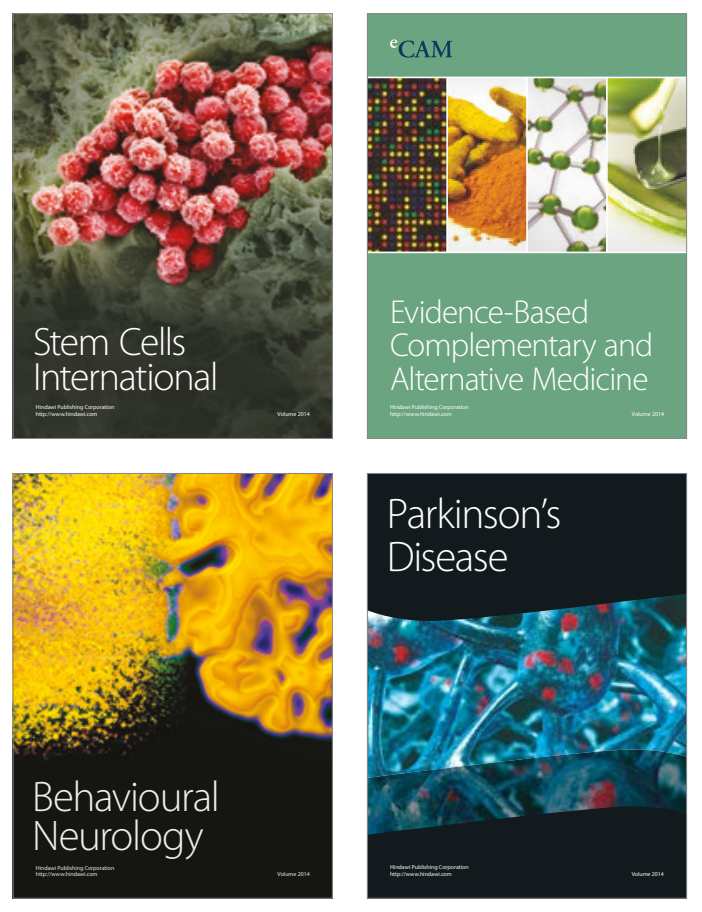
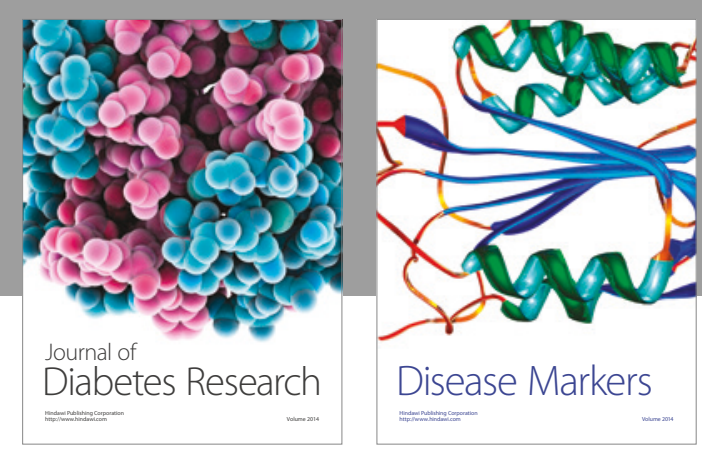

Disease Markers
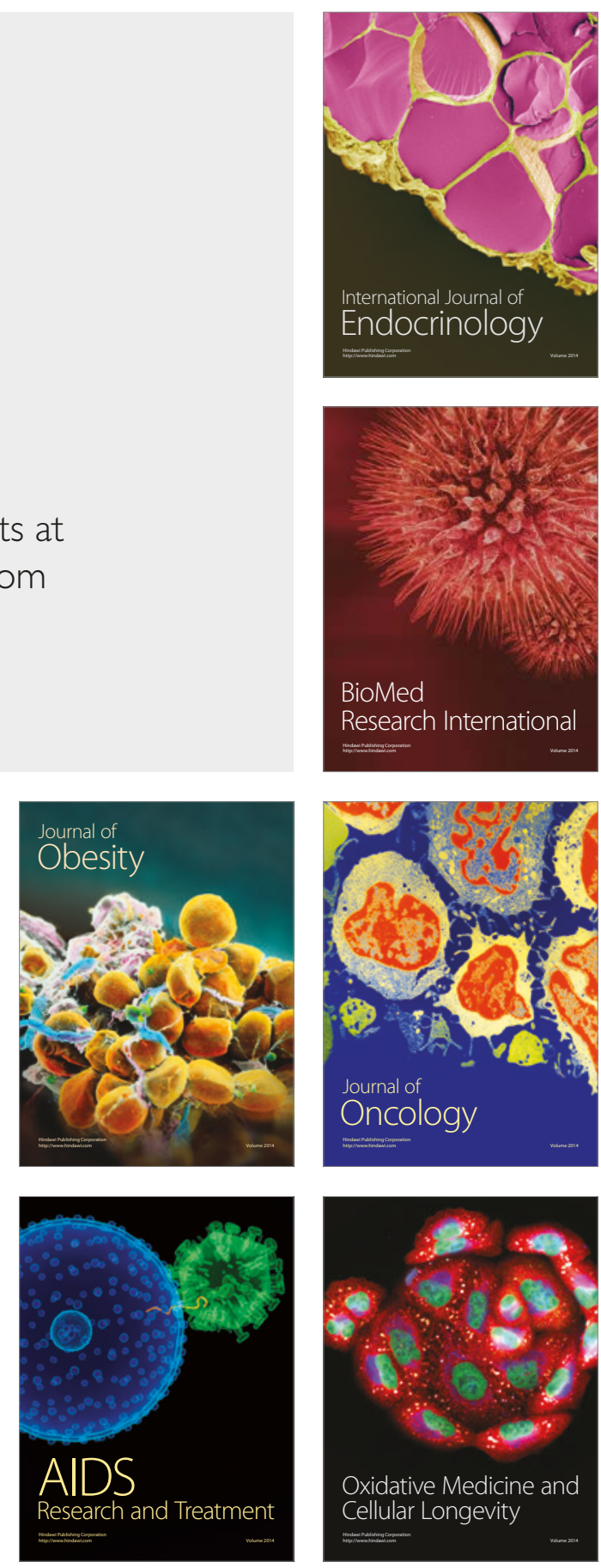